\title{
Doyne lecture 2016: intraocular health and the many faces of inflammation
}

AD Dick $1,2,3$

\begin{abstract}
Dogma for reasons of immune privilege including sequestration (sic) of ocular antigen, lack of lymphatic and immune competent cells in the vital tissues of the eye has long evaporated. Maintaining tissue and cellular health to preserve vision requires active immune responses to prevent damage and respond to danger. A priori the eye must contain immune competent cells, undergo immune surveillance to ensure homoeostasis as well as an ability to promote inflammation. By interrogating immune responses in non-infectious uveitis and compare with age-related macular degeneration (AMD), new concepts of intraocular immune health emerge. The role of macrophage polarisation in the two disorders is a tractable start. TNF-alpha regulation of macrophage responses in uveitis has a pivotal role, supported via experimental evidence and validated by recent trial data. Contrast this with the slow, insidious degeneration in atrophic AMD or in neovasular AMD, with the compelling genetic association with innate immunity and complement, highlights an ability to attenuate pathogenic immune responses and despite known inflammasome activation. Yolk sac-derived microglia maintains tissue immune health. The result of immune cell activation is environmentally dependent, for example, on retinal cell bioenergetics status, autophagy and oxidative stress, and alterations that skew interaction between macrophages and retinal pigment epithelium (RPE). For example, dead RPE eliciting macrophage VEGF secretion but exogenous IL-4 liberates an anti-angiogenic macrophage sFLT-1 response. Impaired autophagy or oxidative stress drives inflammasome activation, increases cytotoxicity, and accentuation of neovascular responses, yet exogenous inflammasome-derived cytokines, such as IL-18 and IL-33, attenuate responses.
\end{abstract}

Eye (2017) 31, 87-96; doi:10.1038/ eye.2016.177; published online 16 September 2016
Introduction

Keeping the peace

To maintain the viability of both a clear media and a functional neuroretina and vision requires an ability to maintain cellular health under stress and to various extents require an orchestration of an immune response. ${ }^{1-3}$

The eye and, in particular, the retina and the choroid, is furnished with a contiguous network of myeloid cells namely-microglia and macrophages. ${ }^{4,5}$ These cells alongside the ascribed non-immune cells (such as retinal pigment epithelium (RPE) and Muller Glia in the retina) establish an immune tissue tone that maintains homoeostasis. Myeloid cell activation in the retina is regulated by a tonic break functioning to prevent overt activation but maintain a scavenger function for daily housekeeping. The argument as to whether microglia contribute to onset of ocular inflammation ${ }^{6}$ is balanced against their homoeostatic role in maintaining a healthy retina, and where data were supportive. ${ }^{2}$ Microglia form a network throughout the retina, and display regulatory phenotypes and functions consistent with other tissue-resident macrophages elsewhere in the body. ${ }^{4}$ Furthermore, although we are still awaiting the advent of live in vivo imaging of immune cell trafficking to understand the dynamics and kinetics of cell trafficking and/or turnover, the results experimentally demonstrate a persistence of macrophages throughout disease $\mathrm{e}^{7,8}$ and where myeloid, macrophage, and T-cell accumulations are noted in later disease. ${ }^{9}$ The activity and extent of immune surveillance and cell traffic is yet to be determined in man.

So one paradigm is that the retina possesses an activation threshold to subvert damage. One example of a tonic break that supports homoeostasis is the regulation of macrophage activation via the cognate receptor interplay of
${ }^{1} \mathrm{UCL}$ Institute of Ophthalmology, London, UK

${ }^{2}$ Academic unit of Ophthalmology, School of Clinical Sciences, University of Bristol, Bristol, UK

${ }^{3}$ National Institute for Health Research (NIHR) Biomedical Research Centre at Moorfields Eye Hospital NHS Foundation Trust and UCL Institute of Ophthalmology, London, UK

Correspondence: AD Dick, UCL Institute of Ophthalmology, 11-43 Bath Street, London EC1V9EL, UK

Tel: +44 (0)20117342 1401. E-mail: a.dick@ucl.ac.uk

Received: 29 June 2016

Accepted: 4 July 2016

Published online:

16 September 2016 
CD200R and its ligand, CD200. CD200 is ubiquitously expressed on macrophages, neurons, and endothelium, ${ }^{10-13}$ and perturbing their interaction results in an aggressive disease phenotype. ${ }^{14,15}$ If we attempt to reconstitute and de-activate macrophage function (by direct ligation of CD200R with anti-CD200R monoclonal antibodies or by a CD200Fc), attenuation of retinal or CNS inflammation can be achieved ${ }^{14,16}$ as well as regulation of other myeloid cells, including mast cells in the lung. ${ }^{17-20}$

How do we keep the peace? A premise lies that there is continual immunosurveillance, akin to CNS, and that alongside the immune cell inhabitants of the retina and choroid, together achieve constant sensing to respond to danger signals. In support, we observe that tissue damage in experimental retinal inflammation is significantly attenuated when macrophages are removed ${ }^{21,22}$ or macrophage/monocyte activation is blocked. ${ }^{16,23-25}$ Experimentally, we observe that the tissue is protected when TNF-alpha activity is neutralised (and indeed show the requisite requirement of TNF for macrophage activation in ocular inflammation ${ }^{26-28}$ ), or by reprogramming macrophage activation threshold with CD200R treatment. These consistent observations have led to a pipeline for therapeutic opportunities to redress activation thresholds of immune cells.

\section{A tail of two conditions}

\section{Understanding uveitis}

Uveitis is defined as an 'orphan disease', yet in 2010 uveitis accounted for $10 \%$ of the estimates of 285 million people visually impaired and 39 million blind. ${ }^{29}$ Non-infectious uveitis comprises a heterogeneous group of disorders diagnosed based on their clinical characteristics and whether or not they are associated with systemic disorders. ${ }^{30,31}$

The health-care burden is significant, where noninfectious uveitis accounts for substantial medical, social, and workload costs in the United Stated of America and aligns with data that persistent disease gives rise to considerable ocular and systemic morbidity. ${ }^{24,32-34}$

The clinical phenotype of non-infectious intraocular inflammation is replicated in experimental animal models that are driven by immune responses to self-antigen. ${ }^{35}$ The animal models, such as experimental autoimmune uveoretinitis (EAU), support a role for autoimmunity with clinical-pathological features bearing remarkable similarity to man. $7,8,36,37$ The currently held notion is that of a CD4 ${ }^{+} \mathrm{T}$ helper cell-driven process and supported in man by the association of sympathetic ophthalmia and Vogt-Koyanagi-Harada disease with specific HLA class II alleles as well as the identification of ocular antigen-responsive $\mathrm{T}$ cells in both the peripheral blood and eyes of patients. ${ }^{38-40}$ When T cells are activated, they assume different functional phenotypes directed through canonical transcription factors ${ }^{41,42}$ and characterised by the secretion of signature cytokines. ${ }^{43,44}$ In EAU, both Th1 and Th17 $\mathrm{T}$ helper cells are important inducers of autoimmune disease. ${ }^{35,45}$ It is the cytokines (especially IFN- $\gamma$ produced by Th1 cells) produced by these cells that activate the non-specific mononuclear tissue infiltration (principally macrophages) and recruit neutrophils as seen in EAU (eg, through interleukin (IL)-17 produced from Th17 cells ${ }^{7,8,23,24,26-28}$ ).

However, some of the uveitic conditions are likely to be driven through both autoinflammatory and autoimmune disease processes. Advances defining the molecular pathology of autoinflammatory conditions have illuminated how many inflammatory diseases are driven by genetic mutations affecting elements of the innate immune system. ${ }^{46}$ For example, in Blau syndrome, there is a gain-of-function mutations in the NOD2 gene driving nuclear factor $\kappa \mathrm{B}$ transcriptional activation ${ }^{47}$ and give rise to early onset inflammatory disease and in the skin there is an abundance of $\mathrm{CD} 4^{+} \mathrm{T}$ cells, $\mathrm{CD} 68^{+}$macrophages, and extensive expression of IFN- $\gamma$, IL-17, and IL- 6 . $^{48}$ Uveitic conditions express changes in inflammasome activation, including Behcet's and spondyloarthropathies. Also the complex interplay between changes in innate immunity, autoinflammation, and autoimmunity implicates an infectious aetio-pathogenesis. The inflammasome is a multiprotein complex comprising a sensor protein, the adaptor protein ASC (apoptosisassociated speck-like domain containing caspase recruitment domain), and the inflammatory protease caspase-1. The eye has many inflammasome-forming sensors ${ }^{49}$ including NLRP receptor molecules (nucleotidebinding domain and leucine-rich repeat containing pyrin domain family). Inflammasome-dependent biological effects may be mediated not only by IL-1b and IL-18, but also by the multifaceted activities of caspase- 1 . Secondary effects of protecting against inflammasome activation, such as when autophagy is increased are observed and has relevance to degenerative disease or remodelling during persistent inflammatory diseases, such as uveitis. ${ }^{50,51}$ The implications of which will be discussed later. It is clear, however that uveitis we observe as a result of autoimmune responses or through activation of cellular pathways linked to autoinflammatory disorders, namely activation of inflammasome, is an appropriate response to the signals received. That is, it is a sequel to an overwhelming adaptive T-cell or innate PAMP-derived response to danger signals. This results in further recruitment of immune cells to the target tissue and these cells inflict the subsequent damage we observe clinically. However, control of responses of both innate and 
adaptive immunity are likely more intertwined. Adaptive responses and T-cell polarisation rely on both close interplay between intracellular complement regulation and NLRP3 assembly. ${ }^{52}$

The knowledge accrued from animal models of uveitis and, in particular, how to subvert tissue damage, has illuminated pivotal role for many targets. The most successful to date is TNF-alpha. ${ }^{1,53}$ Controlling the macrophage response is a principal effect of anti-TNFalpha agents. The ability of macrophages to respond to environmental, cytokine, and receptor signals provides adaptability in controlling inflammation and in restoring structure and function. ${ }^{54}$ Translation will remain challenging (given the plasticity of myeloid cells and how rapidly they adapt) when considering timing of treatment. In EAU there are other compounding influences to consider for therapy and, in particular, whether such mechanisms exist for translation for AMD therapeutics. For example, complement is activated during disease, while arguably not critical to the development of inflammation and suppressing or regulating complement diminishes EAU expression. ${ }^{55-57}$ A convergent mechanism of action is at the level of suppressing macrophage activation. Similarly, chemokine gradient support or perturbation can suppress or exacerbate EAU disease, where the myeloid compartments are being manipulated. ${ }^{58-62}$

For targeting TNF-alpha, we now have substantial evidence through randomised clinical trials exhibiting successful outcomes. The AbbVie (AbbVie Inc., North Chicago, IL, USA)-sponsored VISUAL trials in adults have shown adalimumab (a humanized anti-TNF-alpha monoclonal antibody) significantly lowered the risk for uveitic flare or vision loss in patients with non-infectious, intermediate, posterior, or panuveitis upon complete prednisone taper in both active (uncontrolled despite 10$60 \mathrm{mg}$ prednisone, VISUAL I) and inactive (corticosteroid dependent on $\geq 10 \mathrm{mg}$ prednisone, VISUAL II) uveitis. The end points were statistically significant in favour of adalimumab reducing the time to treatment failure (hazard ratio $(\mathrm{HR})=0.56(0.40-0.76, P<0.001)$ for VISUAL I and HR $=0.52(0.37-0.74, P<0.001)$ for VISUAL II). ${ }^{63}$ The safety profile was consistent with the known safety profile across the approved ADA indications and the patient population. In children, the SYCAMORE randomised placebo-controlled trial looking at effectivity and safety of adalimumab therapy in methrotrexateresistent JIA-Uveitis provides evidence of efficacy of adalimumab treatment used in addition to methotrexate. The final analysis of the primary outcome of time to treatment failure showed a positive treatment effect in favour of adalimumab: $\mathrm{HR}=0.27$ (95\% CI 0.13-0.52); $P<0.0001 .^{64}$

\section{Age-related macular degeneration (AMD) and altered immunity}

AMD, as the leading cause of central visual loss affects the choriocapillaris, Bruch's membrane, and the RPE, with dysfunction and death of overlying photoreceptors. If we compare patients with some of the end stage features of non-infectious uveitis patients, we observe similar. Complement and innate immune gene polymorphisms have been clearly implicated in the development of AMD. ${ }^{65-67}$ While differences in complement regulation between those with the variant and the wild-type alleles have been reported as well as the impact of rare variants in the rapidity of disease onset, ${ }^{68}$ functional immune mechanism remain elusive, particularly with respect to $\mathrm{CFH}$. We have shown that $\mathrm{CFH}$ binds mCRP to dampen its pro-inflammatory activity. CFH from AMD patients carrying the 'risk' His402 polymorphism display impaired binding to mCRP, and therefore pro-inflammatory effects of mCRP remain unrestrained, at least in vitro. ${ }^{69}$ Whether this translates to disease or not requires validation but even so alone does not account for all the immune-related changes we observe in AMD.

It is clear that immune dysregulation exists and data continues to further illuminate the original notion. ${ }^{70}$ Drusen are immunologically active deposits containing oxidative lipids, lipofuscin, complement, and other immune activating components that develop as the consequence of RPE stress and altered tissue homoeostasis. ${ }^{70,71}$ Degenerating RPE is also a major source for drusen components, indicating that age-related changes in RPE may be a causal factor and drive disease progression as we will discuss further. ${ }^{72}$ For example, cells from eyes with AMD exhibit upregulated expression of immune receptors and molecules, ${ }^{73,74}$ including expression of IL-17RC, a receptor for a dimer of IL-17A and IL-17F and activation of NLRP3 inflammasome, that promotes cleavage of pro-IL-1beta and IL-18. ${ }^{75-77}$

Furthermore, both macrophages and multinucleated giant cells, mainly associated with vascular channels and breaks in Bruch's membrane are evident. ${ }^{78-83}$

Macrophage subtype changes have been noted in the eyes of patients with AMD, including a change in the M1/M2 ratio in AMD eyes, compared with that in control eyes of the same age. ${ }^{83}$ With all the data demonstrating immune activation, we need to reconcile these findings with the knowledge that the development of AMD is slow. First, given that AMD is insidious, altered immune responses within the tissue likely occur as a result of persistent lifetime oxidative stress and changes to cell health in the retina. In such conditions, a concept of para-inflammation emerges, ${ }^{3,84}$ where evidence of activated immunity (complement, antibody deposition, macrophage, and 
microglia activation) serves to protect the tissue and prevent overt inflammation and tissue destruction. Does this demonstrate the success of active immune regulation in the eye? Second, the inflection to a more rapid progression (if indeed that occurs) may be co-incident to the heightened inflammasome activation. The consequence is a switch to a more 'classical' chronic inflammatory responses propagating tissue destruction and angiogenesis and as 'frame-shots' of evidence in man supports. ${ }^{3,85-87}$ The cause of change from parainflammation to chronic inflammation remains unknown. We can however make inroads and unwrap possible mechanisms for AMD by comparing with immunemediated uveitis and the role of innate immunity and, in particular, macrophages.

\section{The altered faces of macrophage activation}

\section{Persistent 'inflammation', altered immunosurveillance, and aberrant healing responses?}

Increasing evidence suggests there is persistent dysregulation of immunosurveillance of the retina following the induction of disease. $7,9,37$ If we take the notion that para-inflammation or any evidence of immune responses reflects active immune regulation, then it is possible that following the original insult or danger signal in inflammatory disease the tissue modifies or heightens immunosurveillance. The result may be predicted (not exclusively) to result in: (i) persistence of inflammatory cells and continued immune-targeted destruction; (ii) persistent tissue remodelling and thus potential altered function as a result of, for example, aberrant wound healing, and (iii) maintained architecture but residual increased numbers of inflammatory cells as a consequence of heightened thresholds (both activation threshold (see above) as well as 'patrolling' cell numbers) to maintain tissue integrity and health.

Talking this further and in support of points (ii) and (iii) above, a principal observation in inflammatory disease, such as murine EAU, is the persistence of inflammation, implying that the threshold of myeloid activation is not reset. It is in this context that 'para-inflammation' is operative or as said above, another way of describing this phenomenon are immune responses to protect tissueheightened immunosurveillance with or without tissue remodelling. In the presence of persistent $\mathrm{T}$-cell responses, the tissue remains vulnerable. A constant macrophage infiltrate remains, although in nearly all models the macrophages exhibit an alternative activation phenotype in later stages (as opposed to the early disease classical activation phenotype) and this again supports the concept of tissue remodelling. Taken together, a consequence of a chronic immune cell infiltrate is persistent tissue remodelling contemporaneous with macrophage/ monocyte activation, of which one hallmark result is angiogenesis. The angiogenic response during persistent tissue immune, cell infiltrate requires an operative CCL2-CCR2 axis, but is also influenced by multifunctional matrix proteins such as thrombospondin-1 (TSP-1). ${ }^{9}$ Subverting the angiogenic response (but without altering the initial inflammation and antigen-specific targeting of tissue) by knocking out matricellular proteins, such as TSP-1, results as expected persistent disease (as observed in wild-type mice ${ }^{88}$ ) but notably results in increased angiogenesis (a detriment to retinal function as observed in neovascular diseases AMD). The results infer that there is matricellular control (eg., TSP) of macrophage activation in terms of remodelling and angiogenesis during T-cell-mediated responses and while initial disease severity is not altered with loss of TSP, regulating tissue remodelling (as determined by extent of angiogenesis) is perturbed.

\section{Macrophage conditioning, angiogenesis, and tissue viability}

As introduced above, the function and phenotype of macrophage subtypes is conditioned by signals encountered within the tissue microenvironment. The paradigm of M1 and M2 macrophages has been studied with respect to angiogenesis. ${ }^{89-92}$ Classical activation generates M1 macrophages, which have proinflammatory functions as we have discussed, operative during inflammation in EAU and impart tissue destruction that is effectively neutralized via blocking TNF-alpha activity. Alternatively activated M2 macrophages confer responses related to wound healing, and are capable of generating VEGF and promoting angiogenesis. However, pathological angiogenesis is observed most commonly in the presence of M2 macrophages. ${ }^{93}$ The role of macrophages in driving a VEGF-dependent angiogenic response remains debatable. Data supported by recent evidence from studies using the laser-induced CNV model show that early initiation of choroidal angiogenesis is dependent upon macrophage phagocytosis of damaged RPE components. This in turn elicits an Arg- $1^{+}, \mathrm{VEGF}^{+} \mathrm{M} 2$ phenotype that is only seen early in the genesis of the angiogenic bed. ${ }^{94}$ Contrary, in an attempt to understand VEGF and upstream players using the mouse CNV models with various conditional inactivation of Vegfa, Hif1a, or Epas1, macrophages were not the source of VEGF. ${ }^{95}$

But yet on the other hand, macrophage subtypes are plastic, and functional outcomes may not be straightforward. For example, IFN- $\gamma$ and TLR4 ligation (with LPS) can generate $\mathrm{VEGF}^{+} \mathrm{M} 1$ macrophages, but $\mathrm{PGE}_{2}$ remains a potent stimulus for the generation $\mathrm{VEGF}^{+}$ M2 macrophages as well, in vitro. So when macrophages 
are alternatively activated via IL- 4 they result in a sFlt-1secreting M2 cell and this is seen in both mouse and man. ${ }^{96}$ In man, macrophages associated with $\mathrm{CNV}$ or in specimens of AMD retina that are assessed using immunohistochemistry confirm the nature of VEGFexpressing $\mathrm{CD} 68^{+}$cells. ${ }^{97}$ Finally, perturbing macrophage function can attenuate neovascularisation in experimental models. ${ }^{98}$

What causes an inflection in immune responses that may drive conversion from early AMD to late stage of AMD? One switch as we discussed above is that of the change from a homoeostatic para-inflammatory response, which may become increasingly operative with age, to an unchecked persistent low-grade inflammatory response resulting in loss of RPE and/or pathological angiogenesis. ${ }^{3}$ We have recently demonstrated that RPE destruction in the model of laser-induced CNV polarizes infiltrating myeloid cells towards a pro-angiogenic phenotype. The latter can be perturbed through the augmentation of inhibitory CD200R signalling or through the administration of Th2 cytokines to either tonically suppress macrophage activation or drive anti-angiogenic function, respectively. ${ }^{94,96,98}$ Thus our data and those from others ${ }^{99,100}$ support the concept that interplay between macrophage and RPE within the subretinal space likely contributes to disease progression.

Autophagy is the central cellular housekeeping function that facilitates the disposal of long-lived, defective organelles (eg., mitochondria), and protein aggregates through 'self-eating' via autophagosomes and lysosomes. ${ }^{101}$ Increasing evidence indicates impaired autophagy is associated with age-related degenerative disorders, highlighted by studies in which pharmacological or genetic manipulation of autophagy pathways can induce cellular and tissue degeneration in vitro and in vivo. ${ }^{102-104}$ In the eye, autophagy is highly active in RPE and photoreceptor cells, and impaired autophagy in RPE leads to RPE transcytosis and exocytosis and early signs of RPE degeneration. ${ }^{104-106}$ Impaired autophagy generates dysfunctional RPE that modulates macrophage responses, driving further cell death and promotes angiogenesis in the eye. ${ }^{107}$ There is therefore a growing body of evidence to support the interaction between RPE degeneration and subsequent macrophage activation that may simulate earlier events occurring in AMD leading to progression of disease and neovascularisation.

Moreover, the activation of the NLRP3 inflammasome (that is almost certainly a protective response initially) provides a rapid response to danger in order to preserve tissue function and integrity. The corollary is that inflammasome activation may also cause tissue damage. NLRP3 inflammasome can 'sense' drusen isolated from human AMD donor eyes that liberates active IL-1 $\beta$ and
IL-18 production. IL-18 however has been shown to protect against the development of choroidal neovascularisation. ${ }^{108}$ Another family member, and in a similar vain is IL-33. IL-33 is unique as it is active without caspase- 1 cleavage and does not require inflammasome activation for secretion and bioactivity. ${ }^{109}$ IL-33 triggers an inflammatory response, recruiting monocytes, contributing to photoreceptor loss in a photoxic retinal model of degeneration ${ }^{110}$ and infers a pathogenic role of endogenous IL-33 and an a priori for neutralising IL-33 to reduce myeloid cell accumulation as a possible intervention. However, as with IL-18, and in consideration of the emerging role of IL-33 in inflammatory disorders ${ }^{111,112}$ and in the absence of progressive cell death, IL-33 regulates tissue responses. IL-33 subverts angiogenesis, via direct inhibition of fibroblasts and endothelial cells that express high levels of ST2, and recombinant IL-33 protects against CNV development. ${ }^{113}$

\section{Ageing, senescence, and bioenergetic sources}

O'Neill highlighted the prominence to the 'Warburg effect' in context to immune responses and the role in the pathogenesis of immune-mediated disorders, such as diabetes and atherosclerosis. ${ }^{114-116}$ Extrapolating from Warburg's original observations that tumour cells undergo a bioenergetic switch (permissive for survival and proliferation), to aerobic glycolysis, we now appreciate that such bioenergetic switch occurs in the ageing and early AMD RPE. The Warburg effect rapidly provides ATP and enhances metabolic pathways to support immune cell function. With age, there is increasing strain on mitochondrial function, autophagy, and mitophagy to maintain cellular and tissue health. A response for the good is to divert energy sources-Warburg effect-to maintain function against the stress, allow an ability to proliferate if required, and respond to the oxygen drain by upregulating transcription factor HIF-1 $\alpha$. However, with that also comes a price: inflammasome activation.

Any cell with mitotic potential may undergo senescence (often associated with ageing), resulting in cell cycle arrest but also a cell with a high metabolic demand and with respect to inflammation a distinct secretory phenotype that promotes inflammation. ${ }^{117}$ The senescent-associated secretory phenotype provokes further immune-mediated deleterious effects on the local tissue microenvironment. Senescence also evokes an anti-Warburg effect. All told, senescence may be a drive of immune-mediated degenerative disorders, such as AMD.

In degenerative disease the Warburg effect may be beneficial. The upregulation of the inflammasome may act to protect cells and subvert angiogenesis as shown 
with IL-18 and IL-33. Such a response, and where we observe inflammation is one of the constituents of the para-inflammatory response we discussed earlier. Para-inflammation works to enable and reset immune thresholds to protect the tissue.

The Immune response work group at the annual Beckman Initiative for Macular Research Conference concluded in 2014 with a provocation and notion that AMD is an inflammatory disease, more permissive with age due to an interaction of an aged systemic immune system with an aged or senescent eye. Immune activation that protects and any dysregulation that promotes damage is orchestrated through a playlist of many of the same players, and not exhaustively, altered intracellular lipid handling, Warburg effect, inflammasome activation, and macrophage activation. However, as discussed here, the outcome is dependent on other interactions and external forces, such as the many associations we appreciate with complement protein polymorphisms that will dictate altered cell responses as well as the insidious and persistent influence of oxidative stress and senescence.

\section{Conflict of interest}

The author declares no conflict of interest.

\section{Acknowledgements}

This work was partly supported by the National Institute for Health Research (NIHR) Biomedical Research Centre based at Moorfields Eye Hospital NHS Foundation Trust and UCL Institute of Ophthalmology. I have been most fortunate to work with excellent colleagues and friends who remain long-standing collaborators. The post-docs and students have been inspirational and driven this work forward. I am therefore indebted to a large number of folk over the years. The lecture has developed from many conversations and the collaborative generation of data. I wish to particularly acknowledge with respect to the work presented here (although worried I will miss so many out deserving of acknowledgement): John Forrester, Lindsey Nicholson, Richard Lee, Robert Nussenblatt, Paul McMenamin, Jon Sedgwick, Dave Copland, Heping Xu, Janet Liversidge, Jian Liu, Sofia Theodoropoulou, Morag Roberston, Claudia Calder, Ben Raveney, Catherine Broderick, Debatri Banerjee, Sarah Doyle, Matt Cambell, Robin Ali, Jim Bainbridge, and Phil Luthert.

\section{Disclaimer}

The views expressed are those of the author(s) (ADD) and not necessarily those of the NHS, the NIHR, or the Department of Health.

\section{References}

1 Dick AD. Road to fulfilment: taming the immune response to restore vision. Ophthalmic Res 2012; 48(1): 43-49.

2 Dick AD, Carter D, Robertson M, Broderick C, Hughes E, Forrester JV et al. Control of myeloid activity during retinal inflammation. J Leukoc Biol 2003; 74(2): 161-166.

$3 \mathrm{Xu} \mathrm{H}$, Chen M, Forrester JV. Para-inflammation in the aging retina. Prog Retin Eye Res 2009; 28(5): 348-368.

4 Forrester JV, Xu H, Kuffova L, Dick AD, McMenamin PG. Dendritic cell physiology and function in the eye. Immunol Rev 2010; 234(1): 282-304.

5 Dick AD, Ford AL, Forrester JV, Sedgwick JD. Flow cytometric identification of a minority population of $\mathrm{MHC}$ class II positive cells in the normal rat retina distinct from CD45 lowCD11b/c+CD4 low parenchymal microglia. Br J Ophthalmol 1995; 79(9): 834-840.

6 Rao NA, Kimoto T, Zamir E, Giri R, Wang R, Ito S et al. Pathogenic role of retinal microglia in experimental uveoretinitis. Invest Ophthalmol Vis Sci 2003; 44(1): 22-31.

7 Kerr EC, Copland DA, Dick AD, Nicholson LB. The dynamics of leukocyte infiltration in experimental autoimmune uveoretinitis. Prog Retin Eye Res 2008; 27(5): 527-535.

8 Kerr EC, Raveney BJ, Copland DA, Dick AD, Nicholson LB. Analysis of retinal cellular infiltrate in experimental autoimmune uveoretinitis reveals multiple regulatory cell populations. J Autoimmun 2008; 31(4): 354-361.

9 Chen M, Copland DA, Zhao J, Liu J, Forrester JV, Dick AD et al. Persistent inflammation subverts thrombospondin-1induced regulation of retinal angiogenesis and is driven by CCR2 ligation. Am J Pathol 2012; 180(1): 235-245.

10 Dick AD, Broderick C, Forrester JV, Wright GJ. Distribution of OX2 antigen and OX2 receptor within retina. Invest Ophthalmol Vis Sci 2001; 42(1): 170-176.

11 Preston S, Wright GJ, Starr K, Barclay AN, Brown MH. The leukocyte/neuron cell surface antigen OX2 binds to a ligand on macrophages. Eur J Immunol 1997; 27(8): 1911-1918.

12 Wright GJ, Jones M, Puklavec MJ, Brown MH, Barclay AN. The unusual distribution of the neuronal/lymphoid cell surface CD200 (OX2) glycoprotein is conserved in humans. Immunology 2001; 102(2): 173-179.

13 Wright GJ, Puklavec MJ, Willis AC, Hoek RM, Sedgwick JD, Brown MH et al. Lymphoid/neuronal cell surface OX2 glycoprotein recognizes a novel receptor on macrophages implicated in the control of their function. Immunity 2000; 13(2): 233-242.

14 Banerjee D, Dick AD. Blocking CD200-CD200 receptor axis augments NOS-2 expression and aggravates experimental autoimmune uveoretinitis in Lewis rats. Ocul Immunol Inflamm 2004; 12(2): 115-125.

15 Broderick C, Hoek RM, Forrester JV, Liversidge J, Sedgwick JD, Dick AD. Constitutive retinal CD200 expression regulates resident microglia and activation state of inflammatory cells during experimental autoimmune uveoretinitis. Am J Pathol 2002; 161(5): 1669-1677.

16 Copland DA, Calder CJ, Raveney BJ, Nicholson LB, Phillips J, Cherwinski H et al. Monoclonal antibody-mediated CD200 receptor signaling suppresses macrophage activation and tissue damage in experimental autoimmune uveoretinitis. Am J Pathol 2007; 171(2): 580-588.

17 Cherwinski HM, Murphy CA, Joyce BL, Bigler ME, Song YS, Zurawski SM et al. The CD200 receptor is a novel and potent regulator of murine and human mast cell function. J Immunol 2005; 174(3): 1348-1356. 
18 Jenmalm MC, Cherwinski H, Bowman EP, Phillips JH, Sedgwick JD. Regulation of myeloid cell function through the CD200 receptor. J Immunol 2006; 176(1): 191-199.

19 Deckert M, Sedgwick JD, Fischer E, Schluter D. Regulation of microglial cell responses in murine Toxoplasma encephalitis by CD200/CD200 receptor interaction. Acta Neuropathol 2006; 111(6): 548-558.

20 Zhang S, Cherwinski H, Sedgwick JD, Phillips JH. Molecular mechanisms of CD200 inhibition of mast cell activation. J Immunol 2004; 173(11): 6786-6793.

21 Caspi RR, Chan CC, Fujino Y, Najafian F, Grover S, Hansen CT et al. Recruitment of antigen-nonspecific cells plays a pivotal role in the pathogenesis of a $\mathrm{T}$ cell-mediated organspecific autoimmune disease, experimental autoimmune uveoretinitis. J Neuroimmunol 1993; 47(2): 177-188.

22 Forrester JV, Huitinga I, Lumsden L, Dijkstra CD. Marrowderived activated macrophages are required during the effector phase of experimental autoimmune uveoretinitis in rats. Curr Eye Res 1998; 17(4): 426-437.

23 Dick AD, Duncan L, Hale G, Waldmann H, Isaacs J. Neutralizing TNF-alpha activity modulates T-cell phenotype and function in experimental autoimmune uveoretinitis. J Autoimmun 1998; 11(3): 255-264.

24 Dick AD, Tundia N, Sorg R, Zhao C, Chao J, Joshi A et al. Risk of ocular complications in patients with noninfectious intermediate uveitis, posterior uveitis, or panuveitis. Ophthalmology 2016; 123(3): 655-662.

25 Dick AD, McMenamin PG, Korner H, Scallon BJ, Ghrayeb J, Forrester JV et al. Inhibition of tumor necrosis factor activity minimizes target organ damage in experimental autoimmune uveoretinitis despite quantitatively normal activated T cell traffic to the retina. Eur J Immunol 1996; 26(5): 1018-1025.

26 Calder CJ, Nicholson LB, Dick AD. A selective role for the TNF p55 receptor in autocrine signaling following IFNgamma stimulation in experimental autoimmune uveoretinitis. J Immunol 2005; 175(10): 6286-6293.

27 Raveney BJ, Copland DA, Calder CJ, Dick AD, Nicholson LB. TNFR1 signalling is a critical checkpoint for developing macrophages that control of T-cell proliferation. Immunology 2010; 131(3): 340-349.

28 Raveney BJ, Copland DA, Dick AD, Nicholson LB. TNFR1dependent regulation of myeloid cell function in experimental autoimmune uveoretinitis. J Immunol 2009; 183(4): 2321-2329.

29 The World Health Report W. Global Data on Visual Impairments. Available at: http:/ / www.who.int/blindness/ GLOBALDATAFINALforweb.pdf (accessed on 21 Jan 2014).

30 Dick AD. Immune mechanisms of uveitis: insights into disease pathogenesis and treatment. Int Ophthalmol Clin 2000; 40(2): 1-18.

31 Sharma SM, Nestel AR, Lee RW, Dick AD. Clinical review: anti-TNFalpha therapies in uveitis: perspective on 5 years of clinical experience. Ocul Immunol Inflamm 2009; 17(6): 403-414.

32 Thorne JE, Skup M, Tundia N, Macaulay D, Revol C, Chao J et al. Direct and indirect resource use, healthcare costs and work force absence in patients with non-infectious intermediate, posterior or panuveitis. Acta Ophthalmol 2016; 94: e331-e339.

33 Kempen JH, Van Natta ML, Altaweel MM, Dunn JP, Jabs DA, Lightman SL et al. Factors predicting visual acuity outcome in intermediate, posterior, and panuveitis: the
Multicenter Uveitis Steroid Treatment (MUST) Trial. Am J Ophthalmol 2015; 160(6): 1133-41 e9.

34 Tomkins-Netzer O, Lightman S, Drye L, Kempen J, Holland GN, Rao NA et al. Outcome of treatment of uveitic macular edema: the Multicenter Uveitis Steroid Treatment Trial 2-Year Results. Ophthalmology 2015; 122(11): 2351-2359.

35 Caspi RR. A look at autoimmunity and inflammation in the eye. J Clin Invest 2010; 120(9): 3073-3083.

36 Chu CJ, Herrmann P, Carvalho LS, Liyanage SE, Bainbridge JW, Ali RR et al. Assessment and in vivo scoring of murine experimental autoimmune uveoretinitis using optical coherence tomography. PLoS One 2013; 8(5): e63002.

37 Copland DA, Wertheim MS, Armitage WJ, Nicholson LB, Raveney BJ, Dick AD. The clinical time-course of experimental autoimmune uveoretinitis using topical endoscopic fundal imaging with histologic and cellular infiltrate correlation. Invest Ophthalmol Vis Sci 2008; 49(12): 5458-5465.

38 Gocho K, Kondo I, Yamaki K. Identification of autoreactive $\mathrm{T}$ cells in Vogt-Koyanagi-Harada disease. Invest Ophthalmol Vis Sci 2001; 42(9): 2004-2009.

39 Islam SM, Numaga J, Fujino Y, Hirata R, Matsuki K, Maeda $\mathrm{H}$ et al. HLA class II genes in Vogt-Koyanagi-Harada disease. Invest Ophthalmol Vis Sci 1994; 35(11): 3890-3896.

40 Kilmartin DJ, Wilson D, Liversidge J, Dick AD, Bruce J, Acheson RW et al. Immunogenetics and clinical phenotype of sympathetic ophthalmia in British and Irish patients. Br J Ophthalmol 2001; 85(3): 281-286.

41 Murphy KM, Reiner SL. The lineage decisions of helper T cells. Nat Rev Immunol 2002; 2(12): 933-944.

42 Murphy KM, Stockinger B. Effector T cell plasticity: flexibility in the face of changing circumstances. Nat Immunol 2010; 11(8): 674-680.

43 Greter M, Heppner FL, Lemos MP, Odermatt BM, Goebels N, Laufer $\mathrm{T}$ et al. Dendritic cells permit immune invasion of the CNS in an animal model of multiple sclerosis. Nat Med 2005; 11(3): 328-334.

44 Yosef N, Shalek AK, Gaublomme JT, Jin H, Lee Y, Awasthi A et al. Dynamic regulatory network controlling TH17 cell differentiation. Nature 2013; 496(7446): 461-468.

45 Luger D, Silver PB, Tang J, Cua D, Chen Z, Iwakura Y et al. Either a Th17 or a Th1 effector response can drive autoimmunity: conditions of disease induction affect dominant effector category. J Exp Med 2008; 205(4): 799-810.

46 Masters SL, Simon A, Aksentijevich I, Kastner DL. Horror autoinflammaticus: the molecular pathophysiology of autoinflammatory disease $\left(^{*}\right)$. Annu Rev Immunol 2009; 27: 621-668.

47 Netea MG, van der Meer JW. Immunodeficiency and genetic defects of pattern-recognition receptors. N Engl J Med 2011; 364(1): 60-70.

48 Janssen CE, Rose CD, De Hertogh G, Martin TM, Bader Meunier B, Cimaz R et al. Morphologic and immunohistochemical characterization of granulomas in the nucleotide oligomerization domain 2-related disorders Blau syndrome and Crohn disease. J Allergy Clin Immunol 2012; 129(4): 1076-1084.

49 Tseng WA, Thein T, Kinnunen K, Lashkari K, Gregory MS, D'Amore PA et al. NLRP3 inflammasome activation in retinal pigment epithelial cells by lysosomal destabilization: implications for age-related macular degeneration. Invest Ophthalmol Vis Sci 2013; 54(1): 110-120. 
50 Nakahira K, Haspel JA, Rathinam VA, Lee SJ, Dolinay T, Lam $\mathrm{HC}$ et al. Autophagy proteins regulate innate immune responses by inhibiting the release of mitochondrial DNA mediated by the NALP3 inflammasome. Nat Immunol 2011; 12(3): 222-230.

51 Shi CS, Shenderov K, Huang NN, Kabat J, Abu-Asab M, Fitzgerald KA et al. Activation of autophagy by inflammatory signals limits IL-1beta production by targeting ubiquitinated inflammasomes for destruction. Nat Immunol 2012; 13(3): 255-263.

52 Arbore G, West EE, Spolski R, Robertson AA, Klos A, Rheinheimer $\mathrm{C}$ et al. $\mathrm{T}$ helper 1 immunity requires complement-driven NLRP3 inflammasome activity in CD4 (+) T cells. Science 2016; 352(6292): aad1210.

53 Dick AD, Forrester JV, Liversidge J, Cope AP. The role of tumour necrosis factor (TNF-alpha) in experimental autoimmune uveoretinitis (EAU). Prog Retin Eye Res 2004; 23(6): 617-637.

54 Robertson MJ, Erwig LP, Liversidge J, Forrester JV, Rees AJ, Dick AD. Retinal microenvironment controls resident and infiltrating macrophage function during uveoretinitis. Invest Ophthalmol Vis Sci 2002; 43(7): 2250-2257.

55 An F, Li Q, Tu Z, Bu H, Chan CC, Caspi RR et al. Role of DAF in protecting against T-cell autoreactivity that leads to experimental autoimmune uveitis. Invest Ophthalmol Vis Sci 2009; 50(8): 3778-3782.

56 Read RW, Szalai AJ, Vogt SD, McGwin G, Barnum SR. Genetic deficiency of C3 as well as CNS-targeted expression of the complement inhibitor sCrry ameliorates experimental autoimmune uveoretinitis. Exp Eye Res 2006; 82(3): 389-394.

57 Read RW, Vogt SD, Barnum SR. The complement anaphylatoxin receptors are not required for the development of experimental autoimmune uveitis. J Neuroimmunol 2013; 264(1-2): 127-129.

58 Crane IJ, McKillop-Smith S, Wallace CA, Lamont GR, Forrester JV. Expression of the chemokines MIP-1alpha, MCP-1, and RANTES in experimental autoimmune uveitis. Invest Ophthalmol Vis Sci 2001; 42(7): 1547-1552.

59 Hashida N, Ohguro N, Nishida K. Expression analysis of cytokine and chemokine genes during the natural course of murine experimental autoimmune uveoretinitis. ISRN Inflamm 2012; 2012: 471617.

60 Keino H, Takeuchi M, Kezuka T, Yamakawa N, Tsukahara R, Usui M. Chemokine and chemokine receptor expression during experimental autoimmune uveoretinitis in mice. Graefes Arch Clin Exp Ophthalmol 2003; 241(2): 111-115.

61 Sonoda KH, Sasa Y, Qiao H, Tsutsumi C, Hisatomi T, Komiyama $\mathrm{S}$ et al. Immunoregulatory role of ocular macrophages: the macrophages produce RANTES to suppress experimental autoimmune uveitis. J Immunol 2003; 171(5): 2652-2659.

62 Su SB, Grajewski RS, Luger D, Agarwal RK, Silver PB, Tang $\mathrm{J}$ et al. Altered chemokine profile associated with exacerbated autoimmune pathology under conditions of genetic interferon-gamma deficiency. Invest Ophthalmol Vis Sci 2007; 48(10): 4616-4625.

63 Jaffe GJ, Thorne JE, scales d, Franco P, Tari SR, Camez A et al. Adalimumab in patients with active, non-infectious uveitis requiring high-dose corticosteroids: the VISUAL-1 Trial. Invest Ophthalmol Vis Sci 2015; 56(7): 3115.

64 Ramanan AV, Dick AD, Jones AP, McKay A, Williamson PR, Compeyrot-Lacassagne $\mathrm{S}$ et al. Adalimumab in combination with methotrexate for the thre treatment of Juvenile
Idiopathic Arthrities associated uveitis: the Sycamore trial. Ann Rheum Dis 2016; 75(suppl2): 264.

65 Hageman GS, Hancox LS, Taiber AJ, Gehrs KM, Anderson DH, Johnson LV et al. Extended haplotypes in the complement factor $\mathrm{H}$ (CFH) and CFH-related (CFHR) family of genes protect against age-related macular degeneration: characterization, ethnic distribution and evolutionary implications. Ann Med 2006; 38(8): 592-604.

66 Edwards AO, Ritter R 3rd, Abel KJ, Manning A, Panhuysen C, Farrer LA. Complement factor $\mathrm{H}$ polymorphism and age-related macular degeneration. Science 2005; 308(5720): $421-424$.

67 Klein RJ, Zeiss C, Chew EY, Tsai JY, Sackler RS, Haynes C et al. Complement factor $\mathrm{H}$ polymorphism in age-related macular degeneration. Science 2005; 308(5720): 385-389.

68 Clark SJ, Schmidt CQ, White AM, Hakobyan S, Morgan BP, Bishop PN. Identification of factor $\mathrm{H}$-like protein 1 as the predominant complement regulator in Bruch's membrane: implications for age-related macular degeneration. J Immunol 2014; 193(10): 4962-4970.

69 Molins B, Fuentes-Prior P, Adan A, Anton R, Arostegui JI, Yague $\mathrm{J}$ et al. Complement factor $\mathrm{H}$ binding of monomeric C-reactive protein downregulates proinflammatory activity and is impaired with at risk polymorphic $\mathrm{CFH}$ variants. Sci Rep 2016; 6: 22889.

70 Hageman GS, Luthert PJ, Victor Chong NH, Johnson LV, Anderson DH, Mullins RF. An integrated hypothesis that considers drusen as biomarkers of immune-mediated processes at the RPE-Bruch's membrane interface in aging and age-related macular degeneration. Prog Retin Eye Res 2001; 20(6): 705-732.

71 Hollyfield JG, Bonilha VL, Rayborn ME, Yang X, Shadrach KG, Lu L et al. Oxidative damage-induced inflammation initiates age-related macular degeneration. Nat Med 2008; 14(2): 194-198.

72 Crabb JW, Miyagi M, Gu X, Shadrach K, West KA, Sakaguchi $\mathrm{H}$ et al. Drusen proteome analysis: an approach to the etiology of age-related macular degeneration. Proc Natl Acad Sci USA 2002; 99(23): 14682-14687.

73 Nussenblatt RB, Liu B, Wei L, Sen HN. The immunological basis of degenerative diseases of the eye. Int Rev Immunol 2013; 32(1): 97-112.

74 Wei L, Liu B, Tuo J, Shen D, Chen P, Li Z et al. Hypomethylation of the IL17RC promoter associates with age-related macular degeneration. Cell Rep 2012; 2(5): 1151-1158.

75 Gelfand BD, Wright CB, Kim Y, Yasuma T, Yasuma R, Li S et al. Iron toxicity in the retina requires Alu RNA and the NLRP3 inflammasome. Cell Rep 2015; 11(11): 1686-1693.

76 Kerur N, Hirano Y, Tarallo V, Fowler BJ, Bastos-Carvalho A, Yasuma $\mathrm{T}$ et al. TLR-independent and P2X7-dependent signaling mediate Alu RNA-induced NLRP3 inflammasome activation in geographic atrophy. Invest Ophthalmol Vis Sci 2013; 54(12): 7395-7401.

77 Tarallo V, Hirano Y, Gelfand BD, Dridi S, Kerur N, Kim Y et al. DICER1 loss and Alu RNA induce age-related macular degeneration via the NLRP3 inflammasome and MyD88. Cell 2012; 149(4): 847-859.

78 Killingsworth MC, Sarks JP, Sarks SH. Macrophages related to Bruch's membrane in age-related macular degeneration. Eye 1990; 4(Pt 4): 613-621.

79 Green WR, Enger C. Age-related macular degeneration histopathologic studies: the 1992 Lorenz E. Zimmerman lecture. Ophthalmology 1993; 100(10): 1519-1535. 
80 Dastgheib K, Green WR. Granulomatous reaction to Bruch's membrane in age-related macular degeneration. Arch Ophthalmol 1994; 112(6): 813-818.

81 Grossniklaus HE, Cingle KA, Yoon YD, Ketkar N, L'Hernault N, Brown S. Correlation of histologic 2-dimensional reconstruction and confocal scanning laser microscopic imaging of choroidal neovascularization in eyes with age-related maculopathy. Arch Ophthalmol 2000; 118(5): 625-629.

82 Grossniklaus HE, Miskala PH, Green WR, Bressler SB, Hawkins BS, Toth C et al. Histopathologic and ultrastructural features of surgically excised subfoveal choroidal neovascular lesions: submacular surgery trials report no. 7. Arch Ophthalmol 2005; 123(7): 914-921.

83 Cao X, Shen D, Patel MM, Tuo J, Johnson TM, Olsen TW et al. Macrophage polarization in the maculae of age-related macular degeneration: a pilot study. Pathol Int 2011; 61(9): 528-535.

84 Medzhitov R. Origin and physiological roles of inflammation. Nature 2008; 454(7203): 428-435.

85 Doyle SL, Campbell M, Ozaki E, Salomon RG, Mori A, Kenna PF et al. NLRP3 has a protective role in age-related macular degeneration through the induction of IL-18 by drusen components. Nat Med 2012; 18(5): 791-798.

86 Lee RW, Nicholson LB, Sen HN, Chan CC, Wei L, Nussenblatt RB et al. Autoimmune and autoinflammatory mechanisms in uveitis. Semin Immunopathol 2014; 36(5): 581-594.

87 Nussenblatt RB, Lee RW, Chew E, Wei L, Liu B, Sen HN et al. Immune responses in age-related macular degeneration and a possible long-term therapeutic strategy for prevention. Am J Ophthalmol 2014; 1581(5-11): e2.

88 Zamiri P, Masli S, Kitaichi N, Taylor AW, Streilein JW. Thrombospondin plays a vital role in the immune privilege of the eye. Invest Ophthalmol Vis Sci 2005; 46(3): 908-919.

89 Dace DS, Khan AA, Kelly J, Apte RS. Interleukin-10 promotes pathological angiogenesis by regulating macrophage response to hypoxia during development. PLoS One 2008; 3(10): e3381.

90 Grossniklaus HE, Ling JX, Wallace TM, Dithmar S, Lawson DH, Cohen C et al. Macrophage and retinal pigment epithelium expression of angiogenic cytokines in choroidal neovascularization. Mol Vis 2002; 8: 119-126.

91 Pugh CW, Ratcliffe PJ. Regulation of angiogenesis by hypoxia: role of the HIF system. Nat Med 2003; 9(6): 677-684.

92 Wu WK, Llewellyn OP, Bates DO, Nicholson LB, Dick AD. IL-10 regulation of macrophage VEGF production is dependent on macrophage polarisation and hypoxia. Immunobiology 2010; 215(9-10): 796-803.

93 Ferguson TA, Apte RS. Angiogenesis in eye disease: immunity gained or immunity lost? Semin Immunopathol 2008; 30(2): 111-119.

94 Liu J, Copland DA, Horie S, Wu WK, Chen M, Xu Y et al. Myeloid cells expressing VEGF and arginase-1 following uptake of damaged retinal pigment epithelium suggests potential mechanism that drives the onset of choroidal angiogenesis in mice. PLoS One 2013; 8(8): e72935.

95 Liyanage SE, Fantin A, Villacampa P, Lange CA, Denti L, Cristante $\mathrm{E}$ et al. Myeloid-derived vascular endothelial growth factor and hypoxia-inducible factor are dispensable for ocular neovascularization-brief report. Arterioscler Thromb Vasc Biol 2016; 36(1): 19-24.

96 Wu WK, Georgiadis A, Copland DA, Liyanage S, Luhmann UF, Robbie SJ et al. IL-4 regulates specific Arg-1 macrophage sFlt-1-mediated inhibition of angiogenesis. Am J Pathol 2015; 185(8): 2324-2335.

97 Skeie JM, Mullins RF. Macrophages in neovascular age-related macular degeneration: friends or foes? Eye 2009; 23(4): 747-755.

98 Horie S, Robbie SJ, Liu J, Wu WK, Ali RR, Bainbridge JW et al. CD200R signaling inhibits pro-angiogenic gene expression by macrophages and suppresses choroidal neovascularization. Sci Rep 2013; 3: 3072.

99 Osusky R, Malik P, Ryan SJ. Retinal pigment epithelium cells promote the maturation of monocytes to macrophages in vitro. Ophthalmic Res 1997; 29(1): 31-36.

100 Ma W, Zhao L, Fontainhas AM, Fariss RN, Wong WT. Microglia in the mouse retina alter the structure and function of retinal pigmented epithelial cells: a potential cellular interaction relevant to AMD. PLoS One 2009; 4(11): e7945.

101 Mizushima N, Levine B, Cuervo AM, Klionsky DJ. Autophagy fights disease through cellular self-digestion. Nature 2008; 451(7182): 1069-1075.

102 Cuervo AM. Autophagy and aging: keeping that old broom working. Trends Genet 2008; 24(12): 604-612.

103 Mizushima N, Yoshimori T, Levine B. Methods in mammalian autophagy research. Cell 2010; 140(3): 313-326.

104 Kaarniranta K, Sinha D, Blasiak J, Kauppinen A, Vereb Z, Salminen A et al. Autophagy and heterophagy dysregulation leads to retinal pigment epithelium dysfunction and development of age-related macular degeneration. Autophagy 2013; 9(7): 973-984.

105 Mitter SK, Rao HV, Qi X, Cai J, Sugrue A, Dunn WA Jr. et al. Autophagy in the retina: a potential role in age-related macular degeneration. Adv Exp Med Biol 2012; 723: 83-90.

106 Wang AL, Lukas TJ, Yuan M, Du N, Tso MO, Neufeld AH. Autophagy and exosomes in the aged retinal pigment epithelium: possible relevance to drusen formation and age-related macular degeneration. PLoS One 2009; 4(1): e4160.

107 Liu J, Copland DA, Theodoropoulou S, Chiu HA, Barba MD, Mak KW et al. Impairing autophagy in retinal pigment epithelium leads to inflammasome activation and enhanced macrophage-mediated angiogenesis. Sci Rep 2016; 6: 20639.

108 Doyle SL, Ozaki E, Brennan K, Humphries MM, Mulfaul K, Keaney J et al. IL-18 attenuates experimental choroidal neovascularization as a potential therapy for wet age-related macular degeneration. Sci Transl Med 2014; 6 (230): 230ra44.

109 Cayrol C, Girard JP. The IL-1-like cytokine IL-33 is inactivated after maturation by caspase-1. Proc Natl Acad Sci USA 2009; 106(22): 9021-9026.

110 Xi H, Katschke Jr KJ, Li Y, Truong T, Lee WP, Diehl L et al. IL-33 amplifies an innate immune response in the degenerating retina. J Exp Med 2016; 213(2): 189-207.

111 Liew FY, Pitman NI, McInnes IB. Disease-associated functions of IL-33: the new kid in the IL-1 family. Nat Rev Immunol 2010; 10(2): 103-110.

112 Xu D, Jiang HR, Kewin P, Li Y, Mu R, Fraser AR et al. IL-33 exacerbates antigen-induced arthritis by activating mast cells. Proc Natl Acad Sci USA 2008; 105(31): 10913-10918. 
113 Theodoropoulou S, Copland DA, Liu J, Dick AD. Role of interleukin 33/ST2 axis in the immune-mediated pathogenesis of age-related macular degeneration. Lancet 2015; 385(Suppl 1): S97.

114 Palsson-McDermott EM, Curtis AM, Goel G, Lauterbach MA, Sheedy FJ, Gleeson LE et al. Pyruvate kinase M2 regulates Hif-1alpha activity and IL-1beta induction and is a critical determinant of the warburg effect in LPS-activated macrophages. Cell Metab 2015; 21(1): 65-80.
115 Palsson-McDermott EM, O'Neill LA. The Warburg effect then and now: from cancer to inflammatory diseases. Bioessays 2013; 35(11): 965-973.

116 Wen H, Ting JP, O'Neill LA. A role for the NLRP3 inflammasome in metabolic diseases-did Warburg miss inflammation? Nat Immunol 2012; 13(4): 352-357.

117 Perez-Mancera PA, Young AR, Narita M. Inside and out: the activities of senescence in cancer. Nat Rev Cancer 2014; 14(8): 547-558. 